\title{
Editorial Foreword 77.1 (February 2018)
}

\section{Our Cover}

This issue's cover photo shows a team of "Miss Etiquette" volunteers rehearsing flower presentation in preparation for the Asian Games in Guangzhou city, China, 2010. Each volunteer must learn a standardized smile, wear a formal costume, and sport a special hairstyle along with learning the proper stance and gestures for the role. Ka-ming $\mathrm{Wu}$, the author of an article in this issue, interviewed many young college women who served as etiquette volunteers at mega events in today's China.

\section{IN THIS IssuE}

The issue opens with "The Rise of Xinjiang Studies: A JAS New Author Forum," an unusually formatted collaborative contribution to our "Trends" genre. Whereas previous "Trends" pieces have typically found one author surveying and assessing recent work on a given subject or theme, this one is a made up of a brief introduction by our Central Asia Book Review Editor, Rian THUM - a specialist in the study of Xinjiang-and a question-and-answer section featuring replies to his queries by five scholars; JUSTIN JACOBS, TOM CLIFF, DAVID BROPHY, KWANGMIN KIM, and MADLEN KOBI; who have recently published their first books on that large region. Xinjiang is currently governed by the Chinese Communist Party as a specially administered part of the People's Republic of China, and has recently garnered headlines both domestically and globally, as PRC state media presents it as a hotbed of terrorist activity while various critics of the Chinese Communist Party argue that Beijing is using isolated acts of violence and global fears of Islamism as excuses to ratchet up ever further the draconian measures it has long employed to control and suppress members of the Uyghur ethnic group. The region has also, as this forum illustrates, attracted more and more varied English-language scholarly attention than it has for many decades, though it may be that this will quickly wane due to the obstacles posed by increased surveillance measures and other moves that make academic work on Xinjiang-never easy for many reasons associated with restricted access and censorship — even harder to carry out. This makes capturing this snapshot of the work of this quintet of Xinjiang specialists - a set of historians and anthropologists that includes scholars who focus on both the past and the present, and who are in some cases either partly or largely concerned with the ethnic Han residents of the territory-particularly valuable.

The rest of the issue, aside from the section given over to our standard set of book reviews, is made up of nine research articles. These range widely when it comes to chronology: for example, one goes back to texts produced more than two millennia ago, while 
another focuses on ritualized displays associated with twenty-first-century sports spectacles. They cover a diverse array of topics: one contributor examines poems, another battles, still others look at scriptural traditions, and one focuses on calligraphy. In terms of discipline, there are pieces written or co-written by scholars working in, among other areas, the following fields: philosophy, art history, cultural anthropology, literature, religious studies, and history. In terms of geographical location, there are multiple authors and co-authors of research articles based in Canada and in the United States, while Hong Kong, France, and Denmark are also represented in the list of research article contributors; in addition, two of the participants in the forum on Xinjiang are based in Australia.

The opening research article is our first ever to use "topic modeling," a data mining technique that looks for patterns in large sets of texts, in this case ones produced in China between the age of Confucius and the time of the Song dynasty (960-1126). Co-authored by an international and interdisciplinary team made up of Ryan Nichols, Edward Slingerland, Kristoffer Nielbo, Uffe Bergerton, Carson logan, and Scott Kleinman, it is titled "Modeling the Contested Relationship between Analects, Mencius, and Xunzi: Preliminary Evidence from a Machine-Learning Approach." The authors rely heavily on digital humanities techniques but supplement this with close reading of texts, a more familiar style of analysis to many JAS readers. It uses very new methods to add a novel dimension to a very old debate: that of the degree to which Mencius and Xunzi, whose most famous texts pull in different directions on various issues, follow in the footsteps of their predecessor Confucius. In addition to shedding light on this specific debate, it addresses in detail the "imposing challenges" the documents in question pose for scholars, which convince them that it is worth using any available techniques to shed light on them, including topic modeling, which "has already become a complementary source of knowledge and information for scholars across the humanities" working on other issues and sets of documents.

The next two pieces take the reader forward in time and to the Korean peninsula, offering two different views of the Late Chosŏn period (1392-1910). The first of the two, literary specialist Ksenia Chizhova's "Bodies of Texts: Women Calligraphers and the Elite Vernacular Culture in Late Chosŏn Korea (1392-1910)," examines "the gendered logic of representation" involved in a "highly aestheticized practice with recognized social importance" involving "exquisite vernacular brushwork," the analysis of which provides a new perspective on the gender politics and culture of that period. The second piece dealing with the Korean past, art historian Maya Stillen's "The Politics of Commemoration: Patronage of Monk-General Shrines in Late Chosŏn Korea," sheds new light on "sociopolitical connections between the capital and the provinces" in the period via case studies of a trio of symbolically charged locales. The sites of interest to Stiller are "three shrines dedicated to meritorious Buddhist monk-generals and martyrs who fought during the Japanese invasions" of the late sixteenth century, and she is concerned in part with the ways that "members of the central elite," both male and female, "supported the construction of the shrines in order to advance their respective political ambitions."

Following this are two works that, while also dealing with Buddhism, focus on Southeast Asia, in one case during a much earlier period and in the other a considerably later time. The first of these is K. W. TAYLOR’s "What Lies Behind the Story of Buddhism in 
Ancient Vietnam?" Its key arguments include a claim that, while the story of Vietnamese Buddhism's origins in roughly the third century CE is often viewed through the lens of Sinitic religious developments, there is "evidence of Hindu elements in Vietnamese texts" relevant to the topic, and a basis for seeing "Tamil Hindu" roots for the temple building and related activities that were going on in "what is now northern Vietnam" in that period. The issue's second work on Southeast Asian Buddhism is Alicia Turner's "Pali Scholarship in Its Truest Sense' in Burma: The Multiple Trajectories in Colonial Deployments of Religion." Turner sets out to answer two questions in this wide-ranging essay: "Why are histories of colonialism and religious transformations in Southeast Asia so often told as inextricably interrelated?" and "Why were Buddhist movements identified as both the locus for resistance to colonialism and a central means of constructing colonial modernity?" In answering these questions, the author emphasizes the need to appreciate the way that "Pali examinations proved fertile grounds for Buddhist laypeople to experiment with multiple interpretations of what Buddhist modernity might mean in Burma."

Following these two pieces on Southeast Asia come a pair of articles on colonial interventions, one case in South Asia during the middle of the nineteenth century, the other in Taiwan during the 1940s. The former is historian Chandra Mallampalli’s “A Fondness for Military Display': Conquest and Intrigue in South India during the First Anglo-Afghan War, 1839-1840." The author uses analysis of the events that led to the downfall of "two Indo-Afghan princes" to "illustrate how discourses originating in one region of imperial conflict"-in this case involving rumors of a "Wahhabi conspiracy" - "could 'travel' to remote regions" of India "evolving along the way," and in the process provide pretexts for "military action and the annexation of territory" by an imperial power. In the other piece in this pair, "From Japanese Soldiers to Chinese Rebels: Colonial Hegemony, War Experience, and Spontaneous Remobilization during the 1947 Taiwanese Rebellion," VICTOR LOuzon examines an episode "known as the February 28 Incident" that has long been "at the center of memory wars in Taiwan," but approaches it in a novel way. Whereas the tendency in much writing on it has been to "focus on the background causes of the Incident and on the role played by the Taiwanese elite," he zeroes in on the actions and later understanding of things done by "grassroots participants" in the event. In particular, he is interested in the ways that "young Taiwanese," who had been brought into Japanese military and paramilitary structures during World War II, put familiar repertoires to novel uses during the events of 1947.

Closing out the main section of the issue are two articles on China, one dealing with Rabindranath Tagore's visit to the country and his influence on Chinese poets in the early 1900s, the other with the gendered dimensions of sports spectacles of the last two decades. In the first of these, "Pan-Asian Poetics: Tagore and the Interpersonal in May Fourth New Poetry," GAL Gvili looks at the influence the great Indian writer's view of "literature as a medium connecting religion, the individual, and the universe" had on figures such as Xu Zhimo and Bing Xin. She argues that, while "Tagore's pan-Asianism failed as a viable political project," this should not lead us to overlook the "powerful resonance" his work and his visit had in the "arena of modern Chinese literature"something that we were reminded of recently when a controversy broke out in China over a provocative new translation of some of his writings. In the final research article 


\section{Editorial Foreword}

of the issue, "Elegant and Militarized: Ceremonial Volunteers and the Making of New Women Citizens in China," ethnographer KA-MING WU takes a close look at the meanings conveyed by the performances of "etiquette volunteers" at Chinese sports spectacles. She presents these "young college women who serve at major national events by greeting guests, ushering, and holding ceremonial ribbons" as doing things that are part of a "new state effort to engineer a model woman citizen by combining the Confucian discourse on etiquette, the communist party-state discourse on militarization and strong womanhood, the communist sport tradition of body training, and the latest initiatives on volunteering." We thus begin and end the section of the issue devoted to research articles with pieces that engage with Confucius, in the first case via analysis of texts associated with him, and in the second, contemporary efforts to blend ideas linked to him with practices rooted in the traditions of the Chinese Communist Party, which in the past vilified him as a feudal figure but now embraces him as a sage to be revered.

\section{Selected Forthcoming Articles in JAS 77.2 (May 2018)}

\section{Reflections}

What's the Matter with "China”? A Critique of Teleological History

Hugh R. Clark

War and Environment on the Korean Peninsula

Introduction to a Forum on War and Environment on the Korean Peninsula, 1598-1965 Albert L. Park

Postwar Pines: The Military and the Expansion of State Forests in Post-Imjin Korea, 1598-1684

JoHN S. LEE

Wartime Forestry and the "Low Temperature Lifestyle" in Late Colonial Korea, 1937-1945

David Fedman

Sowing War, Reaping Peace: United Nations Resource Development Programs in the Republic of Korea, 1950-1953

LiSA M. BRADY

The Reshaping of Landscapes: Mediation and Slow Violence

Albert L. Park

Woods and Warfare in Korea and the World: A View from China Micah Muscolino 
Research Articles

New Wine in an Old Bottle: Female Politicians, Family Rule, and Democratization in Thailand

YoshiNORI NisHIZAKI

Mediated Massacre: Digital Nationalism and History Discourse on China's Web

Florian Schneider

Occulting the Dao: Daoist Inner Alchemy, French Spiritism, and Vietnamese Colonial Modernity in Caodai Translingual Practice

Jeremy Jammes and David A. Palmer

Hungry in Japan: Food Insecurity and Ethical Citizenship

Aya H. Kimura

A Careful Village: Comedic Dialogues and Linguistic Modernity in China’s Tibet Timothy Thurston 